\title{
A Novel Monolithic Micropower Amplifier Using a SiGe n-MODFET Device
}

\author{
A.Vilches, and K. Fobelets. \\ Optical and Semiconductor Devices, Department of Electrical and Electronic \\ Engineering, Imperial College London, Exhibition Road, London SW7 2BT. \\ K. Michelakis, S. Despotopoulos, and C. Papavassiliou.
}

Analogue Electronics, Department of Electrical and Electronic Engineering, Imperial College London, Exhibition Road, London SW7 2BT.

T. Hackbarth, and U. König

Daimler Chrysler Research Center, D-89081 Ulm, Germany

Contact email: a.vilches@,imperial.ac.uk

Abstract

A micropower-relevant model is extracted from the DC characteristics of an n-type buried channel Si/SiGe HMODFET (Hetero-junction Modulation Doped FET). This model is then used to design a novel monolithic SiGe single-stage class-A power amplifier for micropower operation (sub $500 \mu \mathrm{W})$. The amplifier is fabricated and measured data of the power-gain versus operating power are presented here for the first time. 


\section{Introduction}

Research on SiGe HMODFETs is motivated by their compatibility with existing CMOS fabrication technology and the promise of superior high-frequency transistor performance when compared to conventional MOSFETs [1]. SiGe HMODFETs contain a buried channel in high mobility strained $\mathrm{Si}$, separated from the gate by further semiconductor layers [2]. The strain in the buried channel and the removal of the carriers from the $\mathrm{SiO}_{2}$ interface, results in that, for a given gate bias, the transconductance $\left(\mathrm{g}_{\mathrm{m}}\right)$ increases more rapidly than is the case for Si MOSFETs and is always higher than in conventional FETs [3]. The extra boost in $\mathrm{g}_{\mathrm{m}}$ at low bias levels warrants the use of these devices in micropower applications where battery life is of prime importance [4]. In this paper we report on a fabricated, SiGe single-stage classA amplifier, for operation at micropower levels, consisting of a monolithically integrated $0.5 \mu \mathrm{m} \times 100 \mu \mathrm{m}$-MODFET and resistive $100 \Omega$ load.

\section{Device Structure and Characteristics}

The n-MODFET structure (see figure 1) was grown by molecular beam epitaxy (MBE) on a $40 \%$ Ge-graded virtual substrate (VS), which was prepared by low energy plasma enhanced chemical vapour deposition (LEPECVD).

A standard fabrication technique for n-type SiGe MODFETs was applied, which included dry MESA etching for electrical isolation of the epitaxial active areas and deposited field oxide for electrical isolation of the implanted areas. The ohmic contacts' implant was P activated by low temperature rapid thermal annealing (RTA). The ohmic contacts consist of $\mathrm{Ti} / \mathrm{Pt} / \mathrm{Au}$ and this metal also serves for the circuit 
interconnections. The Schottky gates were defined by e-beam lithography and lift-off and consisted of $\mathrm{Pt} / \mathrm{Au}$. The minimum gate length available on-wafer was 0.1 microns and a number of test devices and structures were available for characterisation including Hall patterns, which were all measured at $300 \mathrm{~K}$. The sheet resistivity of the structure was $811 \Omega /$ square, the sheet electron density was $4.5 \times 10^{12} \mathrm{~cm}^{-2}$ and the corresponding mobility was $1700 \mathrm{~cm}^{2} / \mathrm{Vs}(300 \mathrm{~K})$.

\section{Device Modelling}

Measured DC current-voltage data was entered into MWOFFICE (Electronic CAD package) [5] and the software was used to successfully fit a Curtice [6] type equivalent circuit model, figure 2 , for operation on micropower supply in the $\mathrm{V}_{\mathrm{DS}}$ range of $0 \mathrm{~V}$ to $0.5 \mathrm{~V}$ and $\mathrm{V}_{\mathrm{GS}}$ range of $-0.5 \mathrm{~V}$ to $0 \mathrm{~V}$, having established that the device's threshold voltage is $-0.5 \mathrm{~V}$.

\section{Amplifier Design}

The single-stage amplifier was simulated in MWOFFICE using the extracted micropower model with an input power level of $-40 \mathrm{dBm}$. The FET is worked into a resistive $100 \Omega$ load and no microwave matching components were used in the initial design as the circuit's bandwidth was expected to be low at the power operation levels targeted. The circuit's input and output are terminated with standard $50 \Omega$ ports and the simulation showed that a maximum transducer power gain of $30 \mathrm{~dB}, \mathrm{G}_{\mathrm{MAX}}$ (see eq. (1)), was achievable with a bias of $\mathrm{V}_{\mathrm{GS}}=-0.2 \mathrm{~V}$ and $\mathrm{V}_{\mathrm{DS}}=0.3 \mathrm{~V}$ (sub $500 \mu \mathrm{W}$ total power supplied). 


$$
G_{M a x}=\frac{\left|S_{21}\right|}{\left|S_{12}\right|}\left(k-\sqrt{k^{2}-1}\right)
$$

where

$$
k=\frac{1-\left|S_{11}\right|^{2}-\left|S_{22}\right|^{2}+\Delta^{2}}{2\left|S_{12}\right|\left|S_{21}\right|}
$$

and

$$
\Delta=S_{11} S_{22}-S_{12} S_{21}
$$

\section{Amplifier Characterisation}

A HP5783D Network Analyser was used to probe, bias and measure the fabricated monolithic amplifier, a picture of which is given in figure 3. Two-port s-parameters were recorded and converted, using MWOFFICE, into $\mathrm{G}_{\text {MAX }}$ versus frequency graphs for each power supply level investigated and a chart of measured power gain at the half-power bandwidth frequency vs. power supplied is shown in figure 4. The graph illustrates that for a supplied power of only $26 \mu \mathrm{W}$, a power gain of $\sim 15 \mathrm{~dB}$ is available with an operating bandwidth of $38 \mathrm{MHz}$.

\section{Conclusion}

A SiGe n-MODFET device has been fabricated, measured and a micropower-relevant model extracted for use in the design of a monolithic single-stage class-A amplifier. The SiGe amplifier was fabricated and a graph of measured maximum power gain vs. power supplied has been presented here for the first time. A minimum operating power of $26 \mu \mathrm{W}$ resulted in a measured power gain of $\sim 15 \mathrm{~dB}$ with a corner frequency of $38 \mathrm{MHz}$. 
Acknowledgment

Financial support from EPSRC award N. GR/N65844/01 is gratefully acknowledged.

\section{References}

1. O'Neill, A. G., and Antoniadis, D. A.: "Investigation of Si/SiGe-Based FET Geometries for High Frequency Performance by Computer Simulation”, IEEE Trans. Electron Devices, Jan. 1997, Vol. 44, pp. 80-88

2. Gluck, M., Hackbarth, T., König, U., Haas, A., Hock, G., Kohn, E.: "High fmax n-type Si/SiGe MODFETs". Electronics Letters, Volume: 33 Issue: 4 , 3 Feb 1997 Page(s): $335-337$

3. Papavassiliou C., Fobelets K., Toumazou C. "SiGe hetero-FET potential for micro-power applications" invited paper, IEICE Trans. Electron, E00-A(2000)

4. Lenk J.D., "Simplifier design of micropower and battery circuits", Butterworth-Heinemann, December 1995, ISBN 0750695102

5. http://www.mwoffice.com/

6. Curtice, W. R., "A Nonlinear GaAs FET Model for Use in the Design of Output Circuits for Power Amplifiers," IEEE Trans. Microwave Theory Tech., Vol. MTT-33, 1983, p.1383. 


\section{Figure captions:}

Fig. 1 : MODFET Device Structure

Fig. 2 : Measured ( $\square$ ) vs. Modelled ( $\Delta$ ) Device Output Characteristics for $\mathrm{V}_{\mathrm{GS}}=-0.5 \mathrm{~V}$ to $0 \mathrm{~V}$

Fig. 3: Micrograph of Fabricated SiGe Amplifier on-wafer

Fig. 4: Measured Amplifier Response for Micropower Operation 
$3.5 \mathrm{~nm}$ Si cap

$6 \mathrm{~nm} \mathrm{SiGe} \mathrm{cap} 40 \%$

$5 \mathrm{~nm} \mathrm{n}^{+}$-SiGe $40 \%$ : Sb supply

$3.5 \mathrm{~nm} \mathrm{SiGe} 40 \%$ spacer

$9 \mathrm{~nm}$ Si channel

$4 \mathrm{~nm} \mathrm{SiGe} 40 \%$ spacer

$5 \mathrm{~nm}$ n-SiGe 40\% :Sb supply

$150 \mathrm{~nm} \mathrm{SiGe} 40 \%$

LEPECVD $40 \% 5 \mu \mathrm{m}$

Silicon substrate: p- $>\mathbf{1 0 0 0} \Omega \mathrm{cm}$

Total MBE Epi: $186 \mathrm{~nm}$

Figure 1

A Novel SiGe Micropower Amplifier Using an n-MODFET Device

A.Vilches, et al. 


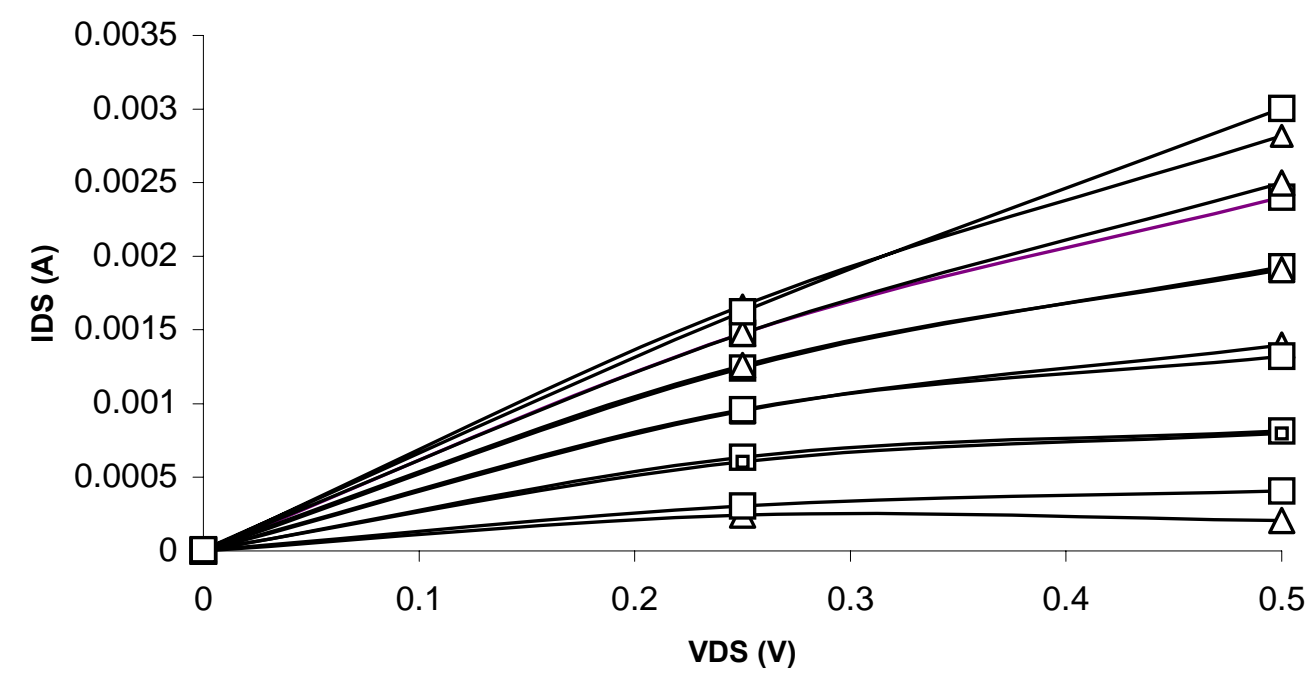

Figure 2

A Novel SiGe Micropower Amplifier Using an n-MODFET Device

A.Vilches, et al. 


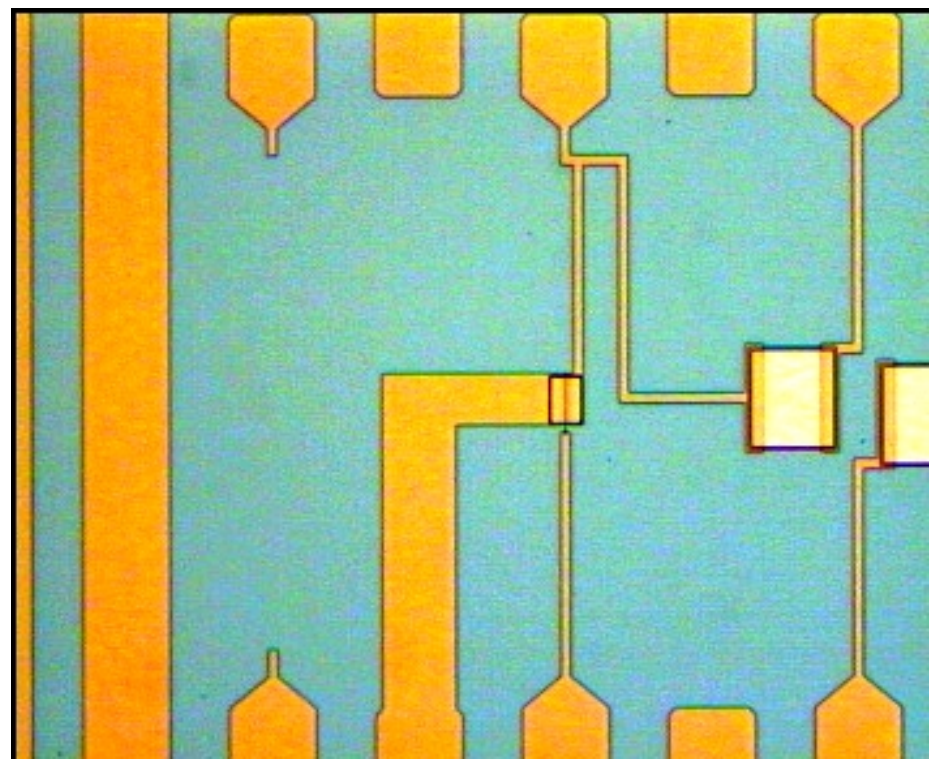

Figure 3

A Novel SiGe Micropower Amplifier Using an n-MODFET Device A.Vilches, et al. 
$\neg-$ Max. Power Gain At Corner Freq. (dB) $-\square-$ Corner Freq. (MHz)

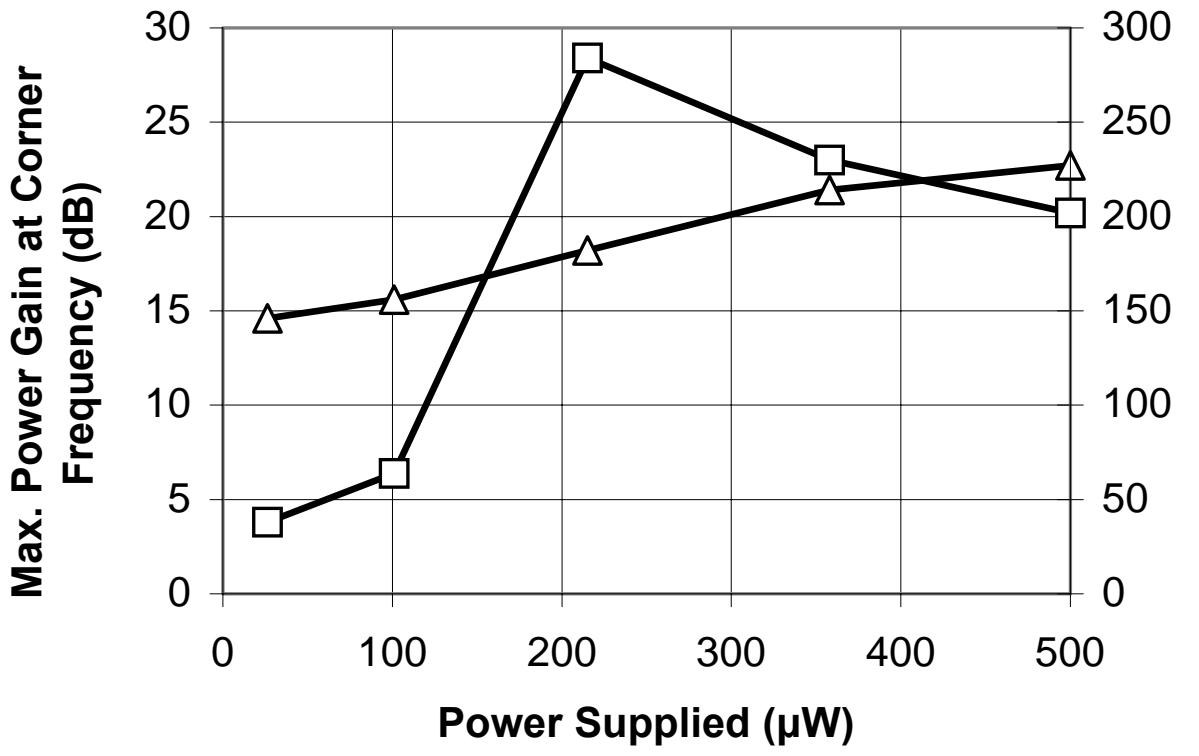

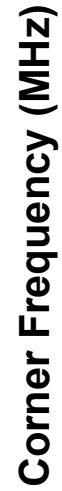

Figure 4

A Novel SiGe Micropower Amplifier Using an n-MODFET Device

A.Vilches, et al. 